\title{
The Effectiveness of Personality-Based Gamification Model for Foreign Vocabulary Online Learning
}

\author{
Hasung Kang, Gede Putra Kusuma* \\ Computer Science Department, BINUS Graduate Program - Master of Computer Science, Bina Nusantara University, Jakarta, \\ Indonesia, 11480
}

\begin{tabular}{l} 
A R T I C L E I N F O \\
\hline Article history: \\
Received: 29 November, 2019 \\
Accepted: 28 February, 2020 \\
Online: 20 March, 2020 \\
\hline
\end{tabular}

Keywords:

Gamification

e-Learning

Personalized Learning

Foreign Language Learning

Big Five Personality

Hybrid Learning Model

\begin{abstract}
A B S T R A C T
Currently, there is a growing interest for applying gamification in e-learning due to innovations in technologies and pedagogies. However, motivation and engagement related problems can arise when the gamification elements are not personalized to match the individual's needs. Therefore, this research proposes a Hybrid Learning Model that combines both Gamification and Personality Traits to increase academic achievement and motivation for students who are studying foreign languages online. The methodology for the Hybrid Learning Model includes three different stages: pre-play stage where the students' personalities are gathered using the Big Five Personality questionnaire, gameplay stage where students' dominant personalities are examined to create gamified learning systems based on the Felder-Silverman Learning Style Model, and the post-play stage where the effectiveness of the Hybrid Learning Model is measured through a recall test to measure achievement and an ARCS motivation questionnaire to measure motivation using various statistical analysis. The Hybrid Learning Model is applied to a language learning web application named VocaManager and tested the Korean vocabulary skills of non-native students who were learning Korean at a local language center in Indonesia. Using SPSS software, the results showed that students who studied under the Hybrid Learning Model had a significant improvement in both their learning achievements and motivation. In addition, the research revealed a significant positive correlation between students' motivation and students' academic achievements.
\end{abstract}

\section{Introduction}

E-learning is currently the largest domain (17.6\%) of trending journal topics within the field of gamification [1]. Current models of gamification in e-learning focus on applying extrinsic game-like elements such as levels, challenges, point systems, and rankings to create a user experience that engages students to complete learning tasks [2]. Popular online language learning applications such as Duolingo has already provided 60 language courses in 23 different languages to its online users [3]. The application integrates gamification principles by implementing ranking systems for its users and providing in-app virtual currencies that can be spent on rewards. While these gamification elements may produce shortterm motivation and engagement, studies from [4] have shown that gamification elements often offer only short-term engagement and a research by [5] have revealed that external rewards tend to eventually undermine students' internal motivation over time. The

"Corresponding Author: Gede Putra Kusuma, inegara@binus.edu research reveals that once the temporary external stimuli from the gamification elements disappear, users' motivation usually disappears along with it.

However, personalization in learning can be a way to increase students' motivation. Researcher [6] applied the Personalized Learning Environment (PLE) system that influenced high motivation scores for engineering undergraduates. The PLE system allowed the students to self-direct their learning process by choosing the course materials and the pace of learning. The students' motivation and satisfaction for learning increased because of their learning environment that supported their personal interests and skills. In an educational context, personalized learning encompasses a diverse range of personalization based on the learners' personal information. However, within e-learning, personalization of learning styles $[7,8]$ and personalities $[9,10]$ are common topics studied among researchers to help improve students' motivation and academic achievements. 
The shortcoming of the current gamification model in eLearning is the lack of personalization of the gamification elements that best fits with each student's individuality. Thus, the purpose of this paper to propose a Hybrid Learning Model that combines both personality and gamification elements to create appropriate learning systems that effectively increase students' motivation and academic achievement. This paper has the following order: 1. Related works on personality based gamification. 2. Background theory and methods. 3. Methodology used for the Hybrid Learning Model and research implementation. 4. Results and discussion of the experiment. 5. Conclusion of the paper along with future studies and improvements.

\section{Related Works}

In recent years, there have been various studies related to personality based gamification for e-learning. Researchers [11] conducted a study on the effectiveness of different e-learning gamification elements based on introvert/extrovert personalities for undergraduate students studying Object Oriented Design Methodology. Similarly, researcher [12] conducted a study on the perceived playfulness or the enjoyment of various gamification elements based on introverted and extroverted personalities for an e-learning system. In both of their studies, the results showed that each personality responded positively and negatively with certain gamification elements. In particular, extrovert learners have positive responses towards more gamification elements such as progress bars and leaderboards whereas introvert learners enjoy using fewer gamification elements.

A different study by [10] applied the Myers-Briggs Type Indicator (MBTI) to determine various learning styles for undergraduate students majoring in Computer Science. The research revealed that students' personalities can be a practical tool to guide appropriate content and structure of computer-based learning systems. Likewise, researchers [13] examined the relationship between personality traits using MBTI and learning styles using the Felder-Silverman Index of Learning Styles for millennial students learning online. The results showed that online learning allows the freedom to create one learning material while implementing various gamification elements that best fits with the students' personalities. In the study, Extrovert/Introvert personality is positively correlated with Active/Reflective learning style, Sensing/Intuitive personality is positively correlated with Sensing/Intuitive learning style, Thinking/Feeling personality is positively correlated with Verbal/Visual learning style, and Judging/Perceiving personality is positively correlated with Sequential/Global learning style.

Researchers [14] measured the drop-out rate and motivation based on the Big Five personality model for high school students learning Microsoft Excel online. The study revealed that for some personality types, the gamification elements helped in increasing motivation while for other personalities types, the gamification elements did not provide much benefit. By depicting the KaplanMeier graphs for gamified and non-gamified learning models for each personality types, highly conscientious learners prefer to have fewer gamification elements to motivate them, whereas highly extraverted learners are motivated by various gamification elements such as badges and points. In addition, highly neurotic learners are negatively affected by gamification elements. While for both agreeableness and openness, the research did not reveal any significant effect due to a small number of these personality types.

Currently, many research related to personality based gamification for e-learning reveal a significant correlation between students' personalities and their interactions with various gamification elements. However, prior studies offer only a few guidance on the effectiveness of applying personality based gamification in real-life learning situations, particularly on how it affects students' academic achievements and motivation. Thus, this study aims to apply the personality based gamification using the Hybrid Learning Model for vocabulary learning online to test whether it significantly improves the students' academic achievements and motivation.

\section{Theory and Methods}

\subsection{Gamification}

Gamification in learning utilizes game elements and systems into a non-game related education context [15]. With improvements in technology, gamification is applied to various elearning scenarios such as Massive Open Online Course and web applications. The main benefits of utilizing gamification in learning is to help increase students' motivation and engagement with the learning material [16]. Researcher [11] summarizes the eight main gamification elements that are commonly used in online education: Points are the currency that measures the success or achievement of learners, Levels represents the difficulty of the learning material along with learners' progression, Leaderboard displays the ranking of all participants' scores to create competition, Progress Bar maps the activities learners have to complete to progress through the course, Feedback is the system's response when learners interact with a learning activity to create engagement, Badges are rewards given upon completion of activities, Chat allows communication with other members to facilitate discussion, and Avatar allows customization of virtual identity such as photos, username, and password.

\subsection{Big Five Personality Traits}

Previous research by [17] confirms that students' personalities can be used to determine a specific learning styles. A wellestablished personality model is the Big Five Personality Traits proposed by Costa and McCrae [18]. It categorizes five different personality traits that are abbreviated as OCEAN (Openness, Conscientiousness, Extraversion, Agreeableness, Neuroticism). To determine an individual's personality, scores are measured for each of the five different personalities and a high score in one personality reveals stronger tendencies specific to that respective personality trait [19]. The explanation of each personalities are as follows:

- Openness is associated with intellectual curiosity. People with Openness personality are usually creative, curious, open-minded, and excited to try out new experiences.

- Conscientiousness relates with the adherence to social norms. People who are conscientious usually have a strong sense of work ethic, responsibility, organization, and performance. 
- Extraversion deals with self-confidence. People who are extraverted usually are energetic, active, talkative, bold, and care little about what others think of them.

- Agreeableness is associated with sociability. People with Agreeableness personality are usually cooperative, kindhearted, trusting, forgiving, and flexible.

- Neuroticism relates with a person's negative emotions. It measures the scale of negative human emotions such as anxiety, instability, insecurity, and social distress.

\subsection{Felder-Silverman Learning Styles}

Learning styles are defined as students' individual way of taking in information and processing their thoughts [20]. The Felder-Silverman Learning Style Model (FSLSM) provides four dimensions of learning styles to categorize students' preferred learning methods [21]. Understanding the different learning styles can help improve students' enjoyment and motivation in learning. The four dimensions of learning styles are as follows:

- Sensing-Intuitive dimension relates to preference on how one perceives or take in information. Sensing learners likes to focus on the concrete examples and strict information while doing practical real-world tasks. Conversely, Intuitive learners tend to think more conceptually and learn information better through theoretical and abstract frames.

- Visual-Verbal dimension relates to the preference on how the information is presented. Visual learners tend to remember things better when they see the related information in forms of visuals such as charts, pictures, and graphs. Verbal learners, on the other hand, tend to remember things that are spoken to them or they have seen in plain writing such as books and documents.

- Active-Reflective dimension relates to the preference on how information is processed. Active learners enjoy processing the information through hand-on interactions with the source material and they prefer large group learning and communication rather than individual learning. Reflective learners, however, prefer thinking and mediating about the learning material alone.

- Sequential-Global dimension relates to the preference on how information is organized and progress toward understanding information. A sequential learner prefers learning in processed step-by-step logical format that has clear objectives. Global learners, however, enjoy a more holistic learning where they can meaningfully piece together random bits of information into one big picture.

\subsection{ARCS Motivation Model}

An established theory in measuring motivation within the context of e-learning is the ARCS Motivation Model proposed by John Keller [22]. Motivation plays an important part in learning because it can be a predictor of academic achievement. A study by [23] reveals that college students with high self-motivation were less prone to dropping out of school compared to their unmotivated peers who had higher dropout rates. The ARCS model measures the following four aspects of motivation in learners:
- Attention refers to how attractive the learning material is to the learner. It relates to learning that incites curiosity and attention for the learner.

- Relevance refers to the relatability between the learning material and the student's personal experience. A relevant learning is one that has a benefit when applying to the student's real-life scenarios.

- Confidence refers to the student's perception on his or her ability to learn and understand the material. A confident learner does not experience anxiety during learning as they are sure that they can do the tasks well.

- Satisfaction refers to the positive feelings the student has towards the learning. A satisfied learner will enjoy the learning process and will likely to continue study the materials.

\section{Methodology}

\subsection{The Hybrid Learning Model}

Expanding on the previous related works, the proposed Hybrid Learning Model combines students' personalities and gamification elements to create specific learning outcomes for e-learning. In particular, this model applies the Big Five Personality Traits, Gamification elements, Felder-Silverman Learning Styles, and the ARCS Motivation to help increase students' academic achievement and motivation. As shown in Figure 1, the Hybrid Learning Model consists of three main stages: Pre-Play stage, Gameplay stage, and Post-play stage.

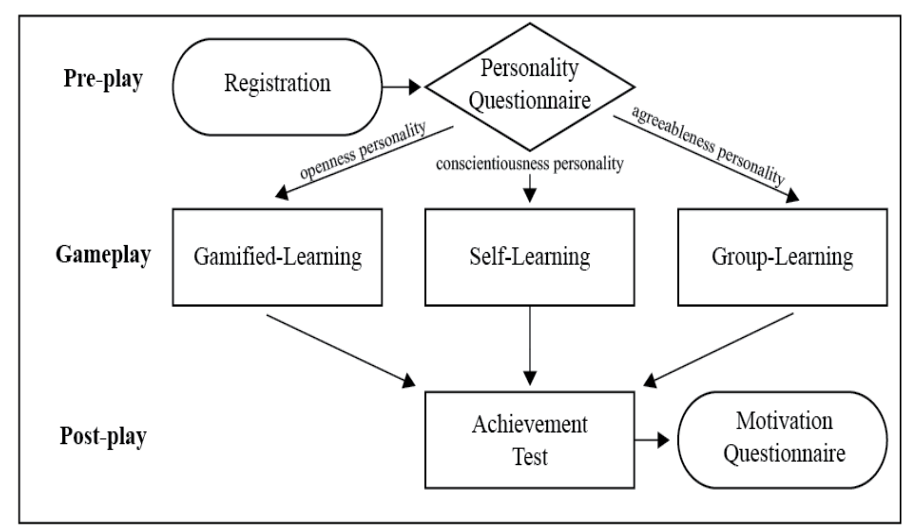

Figure 1: The proposed Hybrid Learning Model

For this research, the Hybrid Learning Model is applied to a web-based Korean vocabulary learning application named "VocaManager." The web application is created using the basic programming languages of HTML, PHP, CSS, JavaScript to create the website interface and MySQL for the database management system. The purpose of the application is to help students effectively learn new vocabulary words everyday by using their personalities to output a specific learning system that best fits the students. In addition, the application functions both on mobile devices and computers to help increase usability. The homepage of "VocaManager" for different devices is shown on Figure 2. As previously mentioned, the core features of the Hybrid Learning Model are the three different stages of pre-play, gameplay, and post-play. 

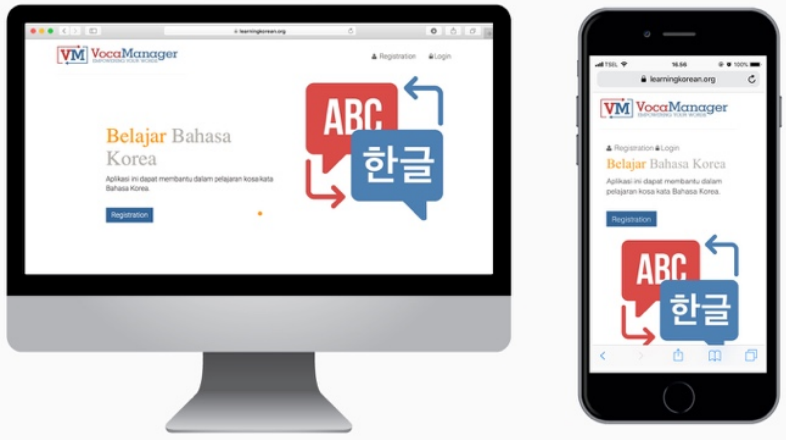

Figure 2: Adaptive display of VocaManager homepage

During the pre-play stage, students' personal information and their personalities are gathered and stored in the database to be used to predict learning styles. When the students first use the learning application, they must create an avatar and register their personal information (name, gender, email) along with their user id and password into the system's database as shown in Figure 3. The system then creates a unique identification number for each student to store their individual personality type along with their motivation and achievement scores.

After the students' initial login, they are redirected to take a personality questionnaire using The Big Five Inventory-2 ExtraShort Form (BFI-2-XS) developed by [24]. Due to the time constrains and to prevent the likelihood of learners to carelessly picking an answer to finish the questionnaire, the experiment used a succinct abridged questionnaire consists of 15 different questions using a 5-point Likert scale ranging from 5 for "strongly agree," down to 1 for "strongly disagree." The application of the pre-play stage is shown in Figure 3.

Once the system has calculated the scores of each of the five personality types, the students move on to the gameplay stage where they will study under specific learning models based on their highest personality trait score.

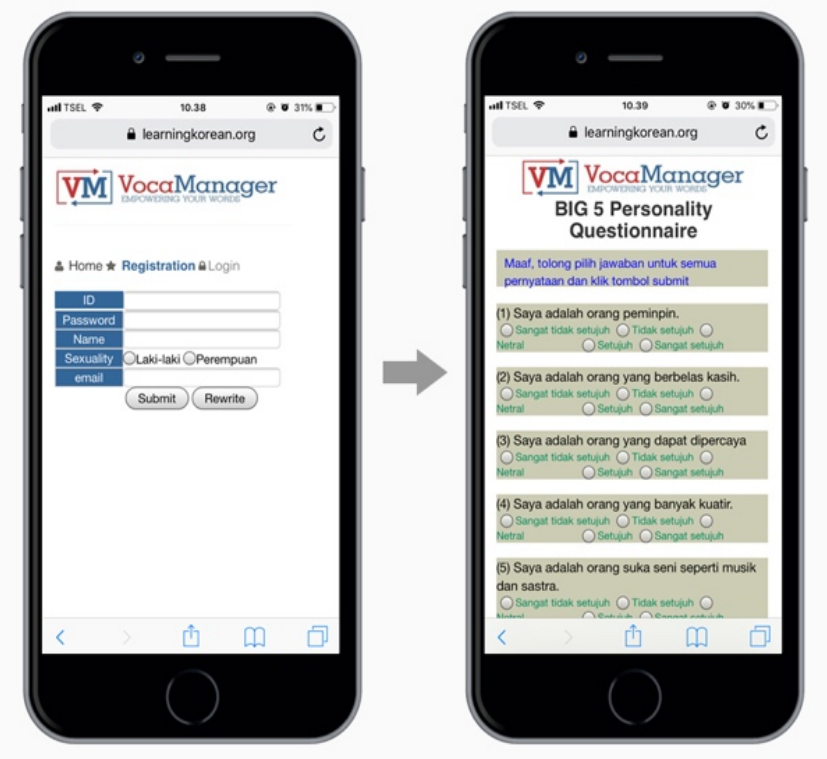

Figure 3: Pre-play: registration and personality questionnaire
As mentioned previously, different personality types react positively or negative to certain learning styles and gamification elements. A research by [25] examined the correlation between students' personality and students' preferred learning style. The research applied the Big Five Personality Traits to measure students' personality and the Felder-Silverman Learning Style Model to match their learning styles. The results highlighted that the students' personalities can be a predictor for their preferred learning styles. A different study by [26] revealed that certain gamification elements and learning activities have a positive impact on learners' motivation based on the Felder-Silverman Learning Style Model. By combining these various research, the proposed Hybrid Learning Model creates unique learning systems that best fit with the students' personalities, as shown in Table 1 .

After determining the students' highest personality scores, the Hybrid Learning Model chooses the appropriate learning system with specific gamification elements. Because only three out of the five personalities (Openness, Conscientiousness, Agreeableness) are considered in this research, if a student scores the highest in either Extraversion or Neuroticism, then the system will choose next highest personality score. In the case of a tie for the highest score, the students take both learning systems and the average scores from both systems will be used for analysis.

Students with Openness personality tend to learn visually and actively. These students retain information better when they are aided with visual graphics. To accommodate this, these students require a gamified learning system with various gamification elements for them to actively learn and explore. The gamification elements that are used are challenge, points, leaderboards, competition, progress bar, and rewards. For the basic challenge, students learn new vocabulary words through randomized alphabet blocks in which students have to click on the respective blocks to form the meaning of the words as shown in Figure 4.

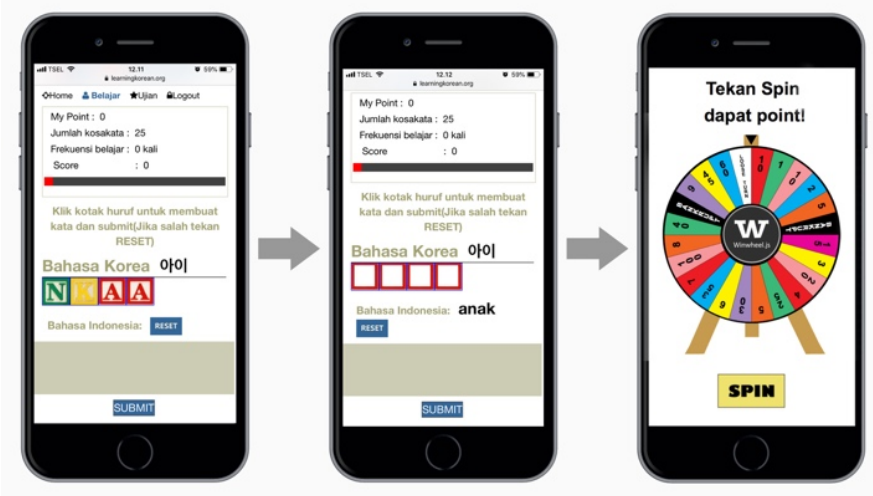

Figure 4: Openness visual learning system

This creates a visual and active learning experience different from the traditional learning method of just simply memorizing the word. This learning model also has an integrated point system. After completing a set of 25 different vocabulary words, students spin the wheel to have the chance to earn variety of points. There is no limit on the amount of times the students can study and spin to earn points. Students' individual points are then displayed on a real-time public leaderboard. At the end of the learning period of three days, the top three students with the highest points on the leaderboard are rewarded with gift cards. 
H. Kang et al. / Advances in Science, Technology and Engineering Systems Journal Vol. 5, No. 2, 261-271 (2020)

Table 1: Gamified learning systems based on the research of Siddiquei [25] and Zaric [26]

\begin{tabular}{|l|l|l|l|}
\hline \multicolumn{1}{|c|}{ Big Five Personality [18] } & \multicolumn{1}{|c|}{$\begin{array}{c}\text { Core Learning } \\
\text { Styles [25] }\end{array}$} & $\begin{array}{l}\text { Preferred Gamification } \\
\text { Elements [26] }\end{array}$ & \multicolumn{1}{|c|}{ Learning Systems [26] } \\
\hline Openness & Visual, Active & $\begin{array}{l}\text { Badges, Leaderboards, } \\
\text { Points, Levels, } \\
\text { Feedback, Time Track, } \\
\text { Progress Bar, } \\
\text { Competition }\end{array}$ & $\begin{array}{l}\text { Questions with visual } \\
\text { elements/pictures }\end{array}$ \\
\hline Conscientiousness & Sensing, Intuitive & $\begin{array}{l}\text { Badges, Levels, } \\
\text { Feedback, Stories, } \\
\text { Progress Bar }\end{array}$ & $\begin{array}{l}\text { Practical tasks with strict } \\
\text { information }\end{array}$ \\
\hline Agreeableness & $\begin{array}{l}\text { Active, Sensing, } \\
\text { Visual, Sequential }\end{array}$ & $\begin{array}{l}\text { Points, Levels, } \\
\text { Feedback, Time Track, } \\
\text { Progress Bar, } \\
\text { Competition }\end{array}$ & $\begin{array}{l}\text { Case studies with multiple } \\
\text { steps }\end{array}$ \\
\hline Extraversion & $\begin{array}{l}\text { Positively } \\
\text { correlated to all } \\
\text { learning styles }\end{array}$ & $\begin{array}{l}\text { All gamification } \\
\text { elements }\end{array}$ & $\begin{array}{l}\text { None; too broad to create a } \\
\text { specific learning system }\end{array}$ \\
\hline Neuroticism & $\begin{array}{l}\text { Negatively } \\
\text { correlated to all } \\
\text { learning styles }\end{array}$ & None & $\begin{array}{l}\text { None; learners don't enjoy } \\
\text { gamification elements }\end{array}$ \\
\hline
\end{tabular}

Students who scored high in conscientiousness are sensing and intuitive learners. They learn information in a systematic and organized way and prefer concrete and practical procedures. As mentioned in a study by [14], highly conscientious learners do not particularly need gamification elements such as points, rewards, and leaderboards to motivate them. However, these students do enjoy the elements of feedback and progress bar within gamification. Thus, for these students, a self-learning system with subtle gamification elements such as logging, repetition, and hints have been applied. As shown in Figure 5, the basic learning task is to type in correct definition, but here students can keep track of their learning progress by seeing their frequency of study or how many times they have completed the lesson.

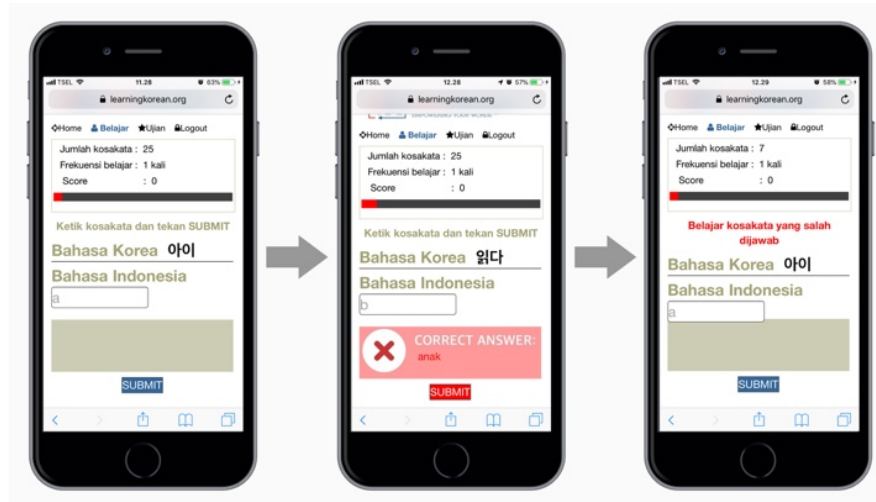

Figure 5: Conscientiousness practical learning system

Students with high agreeableness enjoy learning that are active, sensing, visual, and sequential. They tend to learn sequentially in small increment steps with the cooperation of other members to motivate one another. For this learning system, students study vocabulary words by participating in a group activity called "Voca Avengers". The main gamification elements that are highlighted in this learning system is the avatar, time tracking, competition, and points. Prior to learning, students first create their unique avenger username and go through answering 25 different vocabulary definitions. Simultaneously, on the back end, the learning system records the students' completion time for each word and stores them into the system database. Thus, students with agreeableness personality will learn by first choosing another student to study with. Here, whoever can type the correct definition faster will receive a score for that respective word as shown in Figure 6. The winner of the round is decided by who has the highest score after 25 vocabulary questions. Similar to the openness learning system, whoever win the match at the end can spin the wheel to earn points that can be later exchanged for gift cards. Furthermore, the completion time of the students are updated in the database after each round if the time completed is faster than the previous time. This is meant to motivate the students study the words faster each time they learn while improving the quality of each other's 
learning. Students can repeat this learning process as much as they desire.

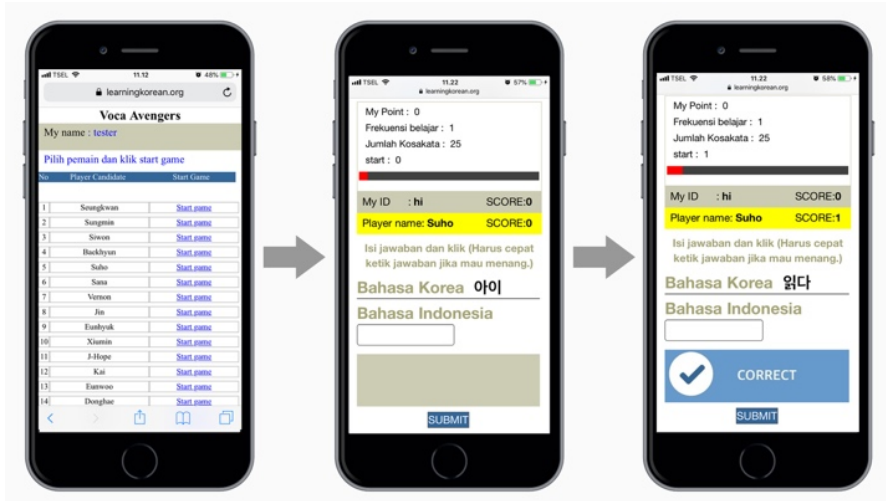

According to a research by [25], students with high extraversion have positive learning tendencies for all the learning styles which are Seeking-Intuitive, Visual-Verbal, ActiveReflective, and Sequential-Global. These students enjoy learning in variety of forms with various gamification elements. Therefore, for the purposes of this research which is to examine specific personality based gamification, the extraversion personality encompasses too broad of learning styles to a concrete learning system with specific gamification elements. Thus, it cannot be created to be objectively measured as it is a combination of all the different learning styles. Students who scored the highest in extraversion will learn based on their second highest personality score.

Contrarily, students with high neuroticism have negative correlation with all of the four learning styles. This coincides with a study by [14] stating that gamification elements have a negative effect on the motivation for highly neurotic learners as they considered the elements to be "silly" and "toylike." These students have low motivation to learn in general as they tend to suffer from anxiety and moodiness. Therefore, it is difficult to determine a specific learning system due to their impulsive behaviors and their lack of interest for learning. Similar to the extraversion personality, for the purposes of this research, a specific learning system cannot be created and these students will learn based on their second highest personality score.

The last stage in the Hybrid Learning Model is the data collection stage. After completing the learning period in the gameplay stage for three days, the following day, students take a vocabulary proficiency test online. The proficiency is measured through a memory-recall test where students have to type in the definition of each vocabulary word within 20 seconds. The time limitation is implemented to help prevent students from looking up the definition elsewhere. The test consists of a total of 25 questions based on vocabulary words the students have learned during the gameplay stage. The test score results are then collected from all the different learning systems and are stored into the database for analysis.

After their proficiency test, students immediately take the ARCS Motivation. The questionnaire measures the scale of students' attention, relevance, confidence, and satisfaction for the learning systems they have used. The questionnaire includes a total of 12 questions ( 3 questions for each variable) based on a 5-point Likert scale from 5 being "strongly agree" to 1 being "strongly disagree." The motivation questions are formed based on a similar study done by [27] to measure student's academic motivation and have been adjusted to fit within the context for vocabulary learning. At the end of questionnaire, students can write their subjective feedback on their learning experience using the hybrid learning model. Figure 7 shows the system's application for the post-play stage.

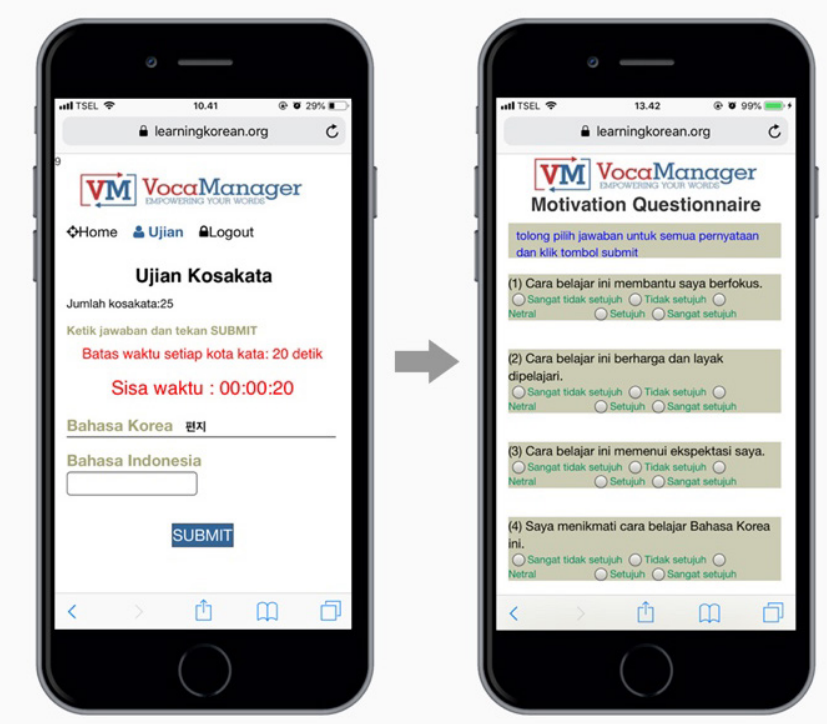

\subsection{Participants}

The research was conducted to all Indonesian students taking the introductory Korean Language course at a Korean Language Center in Indonesia. Due to the limited number of Indonesian students studying Korean, 33 students participated in the experiment. The participants consisted of 31 females and 2 males and were between the ages of 18 and 27 years old interested in learning Korean. The majority of the participants were female due to the growing interest of Korean pop music and Korean dramas among young female adolescent in Indonesia. The learning objective for the experiment was to learn 100 different Korean vocabulary words from TOPIK (Test of Proficiency in Korean) to help prepare the students who wished to take the TOPIK exam.

\subsection{Research Implementation}

The purpose of this research is to test whether the proposed Hybrid Learning Model as applied to vocabulary learning online is effective in increasing motivation and academic achievements. To confirm or deny this, two different learning models for studying 25 vocabulary words were presented to the students: the non-hybrid model and the hybrid model. As shown in Figure 8, the non-hybrid model is also a web learning application, but it does not include gamification elements such as leaderboards, points, and levels. Also, the students do not take the personality questionnaire prior to learning. The basic learning system for the non-hybrid model is that the students type in the definition and the system has a binary response of either "correct" and "incorrect" with the correct definition. It mimics the traditional method of learning vocabulary online. However, for the proposed hybrid model, students must 
first take a personality questionnaire online and based on their personality scores, the application determines a learning system with specific gamification elements as discussed previously.

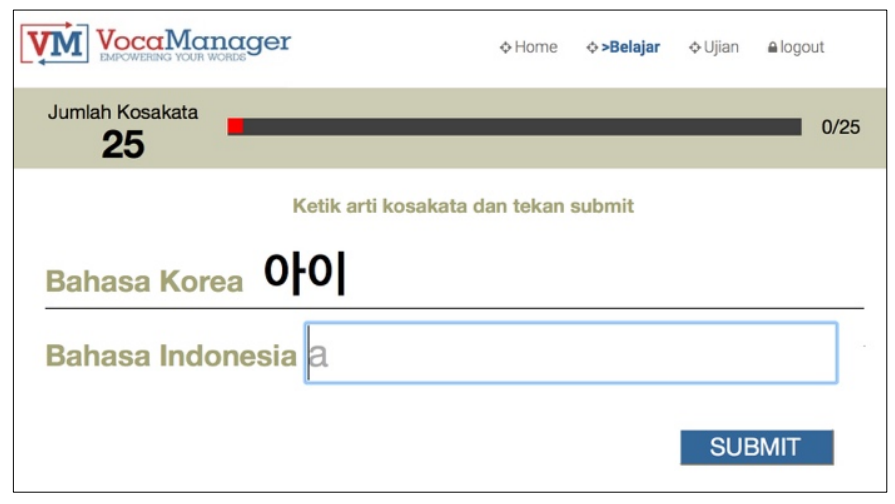

Figure 8: Non-hybrid learning system without gamification

The participants went through four learning intervals, learning 25 vocabulary words each interval, over a two-week period. In the first week, all the students had two learning intervals using the nonhybrid model. Each learning intervals lasted for three days, and on the fourth day students took the both the proficiency test and the motivation questionnaire. On the second week, the students had two learning intervals using the hybrid model. Similarly, after each learning intervals, students took the proficiency test and the motivation questionnaire. After two weeks of learning, the proficiency test and motivation scores from both models were analyzed and compared.

\subsection{Hypotheses}

Current research finds a positive effect and correlation for personality based gamification. Thus, this research hypothesizes that students learning with the hybrid model would be more motivated to learn and produce higher academic achievements than students using the non-hybrid model. In addition, this research seeks to find if there is any correlation between students' motivation and achievements, and to check whether motivation can affect academic achievements and vice versa. The three main hypotheses are summarized as follows:

- H1: The Hybrid Learning Model will increase students' motivation.

- H2: The Hybrid Learning Model will increase students' academic achievements.

- H3: There is a correlation between students' motivation and achievements.

\section{Results and Discussion}

\subsection{Validity and Reliability Test}

Prior to testing the main hypotheses, a validity and reliability test was conducted for both the Big Five Personality Questionnaire and the ARCS Motivation Questionnaire to examine whether the dataset can be analyzed scientifically. A concurrent validity was tested by comparing similar questionnaires from [24, 27] and finding the Pearson Product Moment Correlation Coefficient to assess the accuracy of the questionnaires. The Pearson Correlation results for the Big Five Personality Questionnaire is shown in Table 2.

Table 2: Big Five Personality questionnaire validity test

\begin{tabular}{|l|l|l|}
\hline Personality Question & Pearson Correlation & Sig. (p) \\
\hline I am leader. & $.667^{* *}$ & .000 \\
\hline I am forgiving. & $.584^{* *}$ & .000 \\
\hline I can be trusted. & $.648^{* *}$ & .000 \\
\hline I worry a lot. & $.554^{* *}$ & .001 \\
\hline I like Arts. & $.592^{* *}$ & .000 \\
\hline I am full of energy. & $.659^{* *}$ & .000 \\
\hline I see the best in people. & $.614^{* *}$ & .000 \\
\hline I am organized. & $.653^{* *}$ & .000 \\
\hline I am emotional. & $.523^{* *}$ & .002 \\
\hline I am creative. & $.607^{* *}$ & .000 \\
\hline I am friendly. & $.592^{* *}$ & .000 \\
\hline I respect others. & $.392^{*}$ & .024 \\
\hline I am resilient. & $.591^{* *}$ & .000 \\
\hline I am often disappointed. & .330 & .060 \\
\hline I am a deep thinker. & $.566^{* *}$ & .001 \\
\hline *. Correlation is significant at the 0.05 level (2-tailed). \\
\hline **. Correlation is significant at the 0.01 level (2-tailed). \\
\hline
\end{tabular}

Table 3: ARCS Motivation questionnaire validity test

\begin{tabular}{|l|l|l|l|l|}
\hline \multirow{2}{*}{$\begin{array}{l}\text { ARCS Motivation } \\
\text { Question }\end{array}$} & \multicolumn{2}{|c|}{ Non-Hybrid } & \multicolumn{2}{|c|}{ Hybrid } \\
\cline { 2 - 5 } & $\begin{array}{l}\text { Pearson } \\
\text { Correlation }\end{array}$ & $\begin{array}{l}\text { Sig. } \\
\text { (p) }\end{array}$ & $\begin{array}{l}\text { Pearson } \\
\text { Correlation }\end{array}$ & Sig. (p) \\
\hline $\begin{array}{l}\text { The learning method } \\
\text { helped me focus. }\end{array}$ & $.781^{* *}$ & .000 & $.808^{* *}$ & .000 \\
\hline $\begin{array}{l}\text { The learning method } \\
\text { is valuable. }\end{array}$ & $.783^{* *}$ & .000 & $.793^{* *}$ & .000 \\
\hline $\begin{array}{l}\text { The learning meets } \\
\text { my expectation. }\end{array}$ & $.743^{* *}$ & .000 & $.805^{* *}$ & .000 \\
\hline $\begin{array}{l}\text { I enjoyed the } \\
\text { learning. }\end{array}$ & $.886^{* *}$ & .000 & $.747^{* *}$ & .000 \\
\hline $\begin{array}{l}\text { The learning method } \\
\text { aroused my learning. }\end{array}$ & $.805^{* *}$ & .000 & $.772^{* *}$ & .000 \\
\hline $\begin{array}{l}\text { The learning method } \\
\text { motivated me to learn } \\
\text { more Korean. }\end{array}$ & $.795^{* *}$ & .000 & $.824^{* *}$ & .000 \\
\hline $\begin{array}{l}\text { I can apply the } \\
\text { learning in daily life. }\end{array}$ & $.869^{* *}$ & .000 & $.852^{* *}$ & .000 \\
\hline $\begin{array}{l}\text { I want to continue to } \\
\text { use the learning } \\
\text { method to study } \\
\text { Korean. }\end{array}$ & $.757^{* *}$ & .000 & $.823^{* *}$ & .000 \\
\hline $\begin{array}{l}\text { The learning method } \\
\text { is interesting. }\end{array}$ & $.811^{* *}$ & .000 & $.711^{* *}$ & .000 \\
\hline $\begin{array}{l}\text { The learning method } \\
\text { helps me prepare for } \\
\text { the TOPIK test. }\end{array}$ & $.749^{* *}$ & .000 & $.815^{* *}$ & .000 \\
\hline $\begin{array}{l}\text { I can complete the } \\
\text { learning method well. }\end{array}$ & $.828^{* *}$ & .000 & $.748^{* *}$ & .000 \\
\hline $\begin{array}{l}\text { I want to continue to } \\
\text { use this learning } \\
\text { method for other } \\
\text { subjects. }\end{array}$ & $.767^{* *}$ & .000 & $.662^{* *}$ & .000 \\
\hline$* *$ Correlation is significant at the 0.01 level $(2-$ tailed) & \\
\hline
\end{tabular}


The results showed that all but the 14th question of "I am often disappointed" has a correlation value greater than .3 , which is an industry standard for a question to be considered valid. The slight margin for the 14th question may have caused by the inherent negative nature of the question where participants may have been uncomfortable to answer it truthfully which skewed the overall correlation. However, since the 14th question measures a person's neuroticism and this study does apply the neuroticism personality in the Hybrid Learning Model, it can be concluded that overall, the Big 5 Personality Questionnaire is considered valid.

Table 3 shows the validity test results for ARCS Motivation Questionnaires for both non-hybrid and hybrid models. In both cases, all the questions have correlation values that are greater than .3 and all questions are statistically significant with a $\mathrm{p}$ value $=$ .000 , making the overall motivation questionnaire valid.

To measure the questionnaires' reliability or the internal consistency, the Cronbach's Alpha was measured for the Big 5 Personality Questionnaire and the ARCS Motivation for NonHybrid and Hybrid models. According to [28], the Cronbach's Alpha has been the standard value in scientific research reported for scale reliability. The Cronbach's Alpha results are shown in Table 4, where $\mathrm{N}$ represents the number of questions that were asked in the questionnaire.

Table 4: Cronbach's Alpha results for all questionnaires

\begin{tabular}{|l|l|l|}
\hline Questionnaire & Cronbach's Alpha & N \\
\hline Big 5 Personality & .843 & 15 \\
\hline Non-Hybrid ARCS Motivation & .945 & 12 \\
\hline Hybrid ARCS Motivation & .941 & 12 \\
\hline
\end{tabular}

For the questionnaire to be considered reliable, the alpha value should equal to or be greater than 0.7 [29]. The results showed that $\alpha=.843$ for the Big 5 Personality Questionnaire, $\alpha=.945$ for the non-hybrid model ARCS Motivation Questionnaire, and $\alpha=.941$ for the hybrid model ARCS Motivation Questionnaire. Since all three of the questionnaires' alpha values were greater than 0.7, the questionnaires were all reliable and consistent.

\subsection{Descriptive Statistics}

Descriptive statistics such as the mean and standard deviation for the achievement test scores were compared for both models as shown in Figure 9. The results showed that both the mean test and motivation scores were higher for students learning with the hybrid model. The mean test scores for the hybrid model was 93.61 out of 100 while the non-hybrid model produced an average score of 68.85. For the achievement test scores, the average score for the hybrid model were 25 points higher than the non-hybrid model. This implies that students with the hybrid model had greater academic success compared to the students with the non-hybrid model. Moreover, the standard deviation for the hybrid model, which was 8.56 , was significantly lower than the non-hybrid model, which was 29.93. This shows that students learning with the hybrid model had less of a wide score gap between the highest score and the lowest score and that the students with the hybrid model produced consistently higher test scores compared to the students learning with the non-hybrid model.

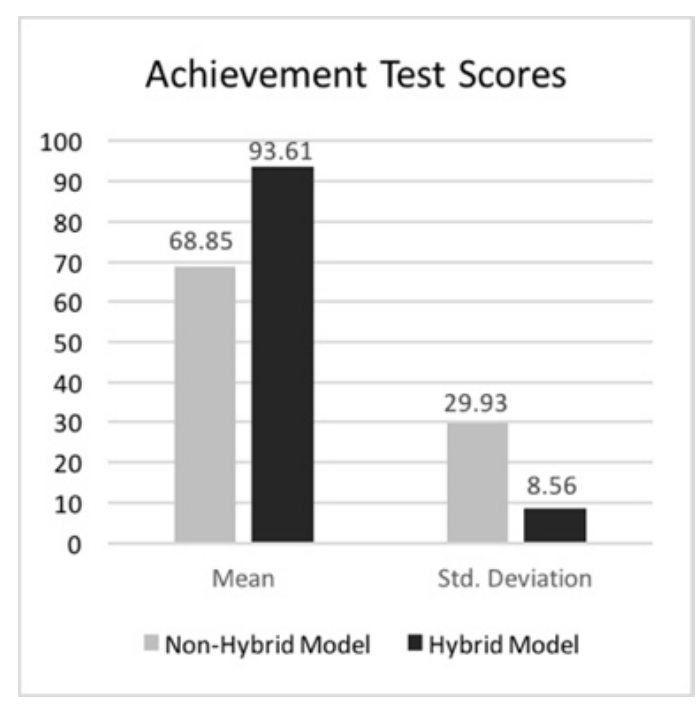

Figure 9: Achievement test scores descriptive statistics

The descriptive statistics for the motivation scores were compared in Figure 10. For the motivation scores, the hybrid model produced an average score of 4.19 while the non-hybrid produced an average score of 3.08. Similarly, the ARCS motivation scores for students learning with the hybrid model was higher by an average of 1 point compared to the non-hybrid model. Since the ARCS motivation scores are based on a 1-5 point Likert scale, a one point difference in motivation score is significant. This implies that students learning with the hybrid model had greater enjoyment and engagement with the learning systems. Furthermore, many students gave the subjective feedback that the hybrid model helped in their learning. However, the standard deviation for the ARCS motivation scores did not differentiate much between the two learning models, which was 0.46 for the hybrid model and 0.56 for the non-hybrid model. This may be caused by the smaller range of possible score outcomes from the 1-5 Likert scale. Regardless, students learning with the hybrid model had greater motivation and enjoyment in their learning compared to students who learned with the non-hybrid model.

\section{ARCS Motivation Scores}

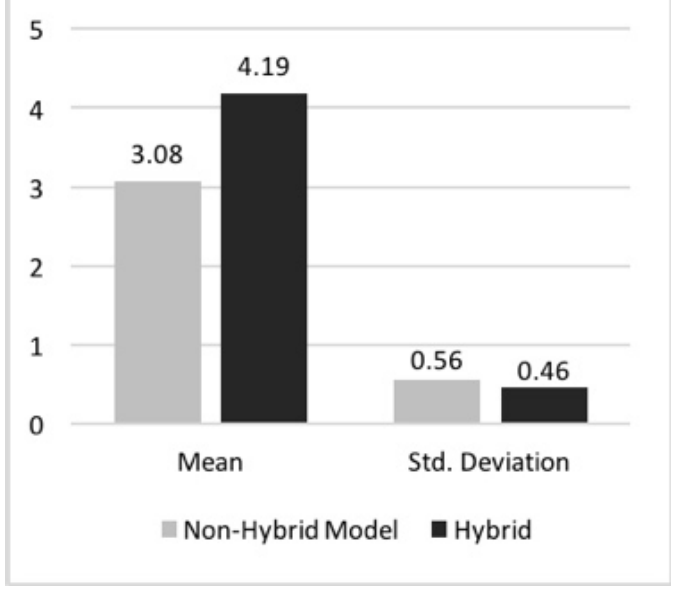

Figure 10: ARCS motivation scores descriptive statistics

Comparing the descriptive statistics for both learning models gives an overview that the hybrid model produced both greater 
achievement test scores and ARCS motivation scores. However, to test scientifically whether a significant difference exists between the two models, a parametric or non-parametric statistics must be conducted depending on the distribution of the datasets.

\subsection{Non-Parametric Statistics}

Prior to testing for significance using parametric statistics, the dataset of the test scores and motivation scores must first be checked for normal distribution [30]. If the dataset is normally distributed, then parametric statistics can be used, but if it is not normally distributed, non-parametric statistics must be utilized to analyze the dataset. Using SPSS software, the Shapiro-Wilk [31] statistical measurement was used to test whether a data sample came from a normal distribution and the results are shown in Table 5.

Table 5: Normality test results using Shapiro-Wilk

\begin{tabular}{|l|l|l|}
\hline \multicolumn{2}{|c|}{ Normality Test } & Shapiro-Wilk Sig. \\
\hline \multirow{2}{*}{ Non-Hybrid } & Test Scores & .002 \\
\cline { 2 - 3 } & Motivation Scores & .003 \\
\hline \multirow{2}{*}{ Hybrid } & Test Scores & .000 \\
\cline { 2 - 3 } & Motivation Scores & .158 \\
\hline
\end{tabular}

A dataset is considered normally distributed when the significance value is greater than .05 . However, the results showed the sig. values of .002, .003, .000, and .158. In fact, all except the hybrid model motivation scores have a significance value that is less than .05 . Three out of the four datasets are not normally distributed. The slightly skewed distribution may have caused by a relatively small sample size of the participants. As a result, to test the three main hypotheses, non-parametric tests must be used when analyzing the test and motivation scores for both the non-hybrid and the hybrid model.

To test $\mathrm{H} 1$ and $\mathrm{H} 2$, the non-parametric Mann-Whitney U test was used to compare the two independent variables, which are the non-hybrid model scores and hybrid model scores. This test is a common alternative to the parametric t-test when the dataset is not normally distributed [32]. The Mann-Whitney U test compares the number of times the scores from the hybrid model ranked higher than the scores from the non-hybrid model. The results are shown in Table 6.

Table 6: Mann-Whitney U test results for significance

\begin{tabular}{|l|l|l|l|l|}
\hline Mann-Whitney U & $\begin{array}{l}\text { Learning } \\
\text { Model }\end{array}$ & $\begin{array}{l}\text { Mean } \\
\text { Rank }\end{array}$ & $\begin{array}{l}\text { Asymp. Sig } \\
\text { (2-tailed) }\end{array}$ & $\mathbf{N}$ \\
\hline \multirow{2}{*}{ Test Scores } & Non-Hybrid & 25.36 & \multirow{2}{*}{.000} & 33 \\
\cline { 2 - 3 } \cline { 5 - 5 } & Hybrid & 41.64 & 33 \\
\hline \multirow{2}{*}{ Motivation Scores } & Non-Hybrid & 23.14 & \multirow{2}{*}{.000} & 33 \\
\cline { 2 - 3 } & Hybrid & 43.86 & 33 \\
\hline
\end{tabular}

The mean rank for the test scores were 41.64 for the hybrid model and 25.36 for the non-hybrid model. As for the motivation scores, the hybrid model had 43.86 mean rank while the nonhybrid model had 23.14 mean rank. The mean ranks for both the test scores and motivation scores in the hybrid learning model were on 18 ranks higher than the non-hybrid learning model. This implies that students who learned with the hybrid model overall had better scores in both their academic test scores and motivation scores when compared to the non-hybrid model. Moreover, since the $p$ value $<.05$ for both the test scores and the motivation scores, there was a significant difference test scores and motivation scores between the two models. These results support hypothesis H1 that the Hybrid Learning Model significantly increases students' academic achievement, and also affirms hypothesis $\mathrm{H} 2$ that the Hybrid Learning Model significantly increases students' motivation.

To test for hypothesis H3, a non-parametric Spearman's Rank Correlation Coefficient test was used to examine the linear relationship between the students test scores and motivation scores. This test is an alternative measurement to the parametric Pearson Product Moment Correlation in comparing the relationships between two variables [33]. The results are shown in Table 7.

Table 7: Spearman's Rank Coefficient Results

\begin{tabular}{|l|l|l|}
\hline Learning Model & $\begin{array}{l}\text { Spearman's rho } \\
\text { correlation coefficient }\end{array}$ & Sig. (p) \\
\hline Non-Hybrid & $.693^{* *}$ & .000 \\
\hline Hybrid & $.755^{* *}$ & .000 \\
\hline **. Correlation is significant at the 0.01 level (2-tailed). \\
\hline
\end{tabular}

In both learning models, the $\mathrm{p}=.000$ which implied a significant correlation between the achievement test scores and motivation scores. The results support hypothesis $\mathrm{H} 3$ that a correlation exists between students' motivation and academic achievement. Moreover, since the Spearman's coefficient was .693 for the non-hybrid model and .755 for the hybrid learning model, there exists a strong positive correlation between students' achievement test scores and motivation scores. This implies that as students' motivation increases so will their academic achievement, and vice versa. The result is consistent with other similar research done by [34] which found a correlation coefficient of .79 between students' learning motivation and achievement for students studying the Indonesian language.

\section{Conclusion}

Many studies have discussed the impact of personality traits on gamification elements when learning online, but few have implemented the effectiveness of personality based gamification in real-life scenarios. Thus, in this research, the Hybrid Learning Model that combines both gamification elements and personality traits was applied to a web learning application named VocaManager that was designed to teach foreign vocabulary words. Based on the experiment, the Hybrid Learning Model resulted in a significant increase in students' motivation and students' academic achievements when compared to the traditional method of learning online. Furthermore, there exists a strong positive correlation between students' motivation and students' achievements. The implication of this study reveals an important innovation for e-learning today. By matching the students' individual personalities with specific gamification elements, students can feel more motivated to learn, which in turn, increases their academic achievement. Justification can be made to choose VocaManager over existing online vocabulary learning systems because VocaManager provides the students with a specific learning environment that best fits their personalities and learning 
styles. This method of learning has proved to be effective because the students showed an increase in their academic achievement and motivation when learning with the hybrid learning model. Moreover, VocaManager provides a unique learning experience that is different from existing learning systems which normally has one type of a learning system. Hence, the majority of the students who learned with VocaManager gave a subjective feedback that they would want to continue learn using VocaManager for their daily vocabulary learning.

The main limitations for this research was the small sample size due to the limited number of students studying at that time. For future research, the participants can be gathered from schools rather than local language centers to increase the number of students available for the experiment. Furthermore, due to the limited research material available, this study did not create specific learning systems for the students with Extraversion and Neuroticism personality. For future studies, however, a more comprehensive research can be done specifically for these two personalities, and finding methods to combine other personality models such as the Myers-Briggs Type Indicator to help create appropriate learning systems for the gaps within Extraversion and Neuroticism personalities. Lastly, for future studies, incorporating other areas of personalization such as gender, age, and demographics using data mining techniques can be further researched to create an even more curated learning systems for the students to improve their learning motivation and academic achievements.

As innovation within e-learning continues to develop and grow, this research paper provides several recommendation to the current e-Learning system. First, online learning should create uniquely different learning systems that are personalized to the individuality of the learners based on their personality, age, gender, and background. Secondly, online learning systems should integrate various academic field of studies into e-Learning such as Computer Science, Psychology, Game Studies, and Design to optimize the learning experience and environment for the learners. Thirdly, it is important for educators today to have a personal understanding of their students in order to create learning materials and environments that best supports the students to succeed. By applying these adjustments, this research paper reveals that not only do the learners increase their academic achievements, but also their motivation to learn the subject material significantly increases.

\section{References}

[1] J. Kasurinen and A. Knutas, "Publication trends in gamification: A systematic mapping study," Computer Science Review, 27, 33-44, 2018. doi:10.1016/j.cosrev.2017.10.003.

[2] F. L. Khaleel, N. S. Ashaari, T. S. M. T. Wook, and A. Ismail, "Gamification Elements for Learning Applications," International Journal on Advanced Science, Engineering and Information Technology, 6(6), 868, 2016. doi:10.18517/ijaseit.6.6.1379.

[3] D. Huynh, L. Zuo, and H. Iida, "Analyzing Gamification of 'Duolingo' with Focus on Its Course Structure," Lecture Notes in Computer Science Games and Learning Alliance, 268-277, 2016. doi:10.1007/978-3-319-50182-6 24.

[4] R. V. Roy and B. Zaman, "Need-supporting gamification in education: An assessment of motivational effects over time," Computers \& Education, 127, 283-297, 2018. doi:10.1016/j.compedu.2018.08.018.

[5] K. Kim and S. J. G. Ahn, "Rewards that undermine customer loyalty? A motivational approach to loyalty programs," Psychology \& Marketing, 34(9), 842-852, 2017. doi:10.1002/mar.21026.

[6] B. Balakrishnan, "Motivating engineering students learning via monitoring in personalized learning environment with tagging system," Computer
Applications in Engineering Education, 26(3), 700-710, 2018. doi:10.1002/cae.21924

[7] S. V. Kolekar, R. M. Pai, and M. P. M.m., "Adaptive User Interface for Moodle based E-learning System using Learning Styles," Procedia Computer Science, 135, 606-615, 2018. doi:10.1016/j.procs.2018.08.226.

[8] Ö. Özyurt and H. Özyurt, "Learning style based individualized adaptive elearning environments: Content analysis of the articles published from 2005 to 2014," Computers in Human Behavior, 52, 349-358, 2015. doi:10.1016/j.chb.2015.06.020.

[9] A. Tlili, F. Essalmi, M. Jemni, Kinshuk, and N.-S. Chen, "Role of personality in computer based learning," Computers in Human Behavior, 64, 805-813, 2016. doi:10.1016/j.chb.2016.07.043.

[10] J. Kim, A. Lee, and H. Ryu, "Personality and its effects on learning performance: Design guidelines for an adaptive e-learning system based on a user model," International Journal of Industrial Ergonomics, 43(5), 450-461, 2013. doi:10.1016/j.ergon.2013.03.001.

[11] M. Denden, A. Tlili, F. Essalmi, and M. Jemni, "Educational Gamification Based on Personality," 2017 IEEE/ACS 14th International Conference on Computer Systems and Applications (AICCSA), 2017. doi:10.1109/aiccsa.2017.87.

[12] D. Codish and G. Ravid, "Personality Based Gamification - Educational Gamification for Extroverts and Introverts," CHAIS '14 - Conf. Study Innov. Learn. Technol. Learn. Technol. Era, 36-44, 2014.

[13] A. Kamal and S. Radhakrishnan, "Individual learning preferences based on personality traits in an E-learning scenario," Education and Information Technologies, 24(1), 407-435, 2018. doi:10.1007/s10639-018-9777-4.

[14] W. Ghaban and R. Hendley, "How Different Personalities Benefit From Gamification," Interacting with Computers, 31(2), 138-153, 2019. doi:10.1093/iwc/iwz009.

[15] D. N. Karagiorgas and S. Niemann, "Gamification and Game-Based Learning," Journal of Educational Technology Systems, 45(4), 499-519, 2017. doi: $10.1177 / 0047239516665105$.

[16] R. S. Alsawaier, "The effect of gamification on motivation and engagement," International Journal of Information and Learning Technology, 35(1), 56-79, 2018. doi:10.1108/ijilt-02-2017-0009.

[17] P. Buckley and E. Doyle, "Individualising gamification: An investigation of the impact of learning styles and personality traits on the efficacy of gamification using a prediction market," Computers \& Education, 106, 4355, 2017. doi:10.1016/j.compedu.2016.11.009.

[18] P. T. Costa and R. R. Mccrae, "The Five-Factor Model and the NEO Inventories," Oxford Handbooks Online, 2009. doi:10.1093/oxfordhb/9780195366877.013.0016.

[19] T. Aidt and C. Rauh, "The Big Five personality traits and partisanship in England," Electoral Studies, 54, 1-21, 2018 doi:10.1016/j.electstud.2018.04.017.

[20] T. A. Litzinger, S. H. Lee, J. C. Wise, and R. M. Felder, "A Psychometric Study of the Index of Learning Styles," Journal of Engineering Education, 96(4), 309-319, 2007. doi:10.1002/j.2168-9830.2007.tb00941.x.

[21] S. Graf, S. R. Viola, T. Leo, and Kinshuk, "In-Depth Analysis of the FelderSilverman Learning Style Dimensions," Journal of Research on Technology in Education, 40(1), 79-93, 2007. doi:10.1080/15391523.2007.10782498.

[22] J. M. Keller, "First principles of motivation to learn and e3-learning," $\begin{array}{lll}\text { Distance } & \text { Education, } & 29(2),\end{array}$ doi:10.1080/01587910802154970.

[23] E. E. Meens, A. W. Bakx, T. A. Klimstra, and J. J. Denissen, "The association of identity and motivation with students academic achievement in higher education," Learning and Individual Differences, 64, 54-70, 2018. doi:10.1016/j.lindif.2018.04.006.

[24] C. J. Soto and O. P. John, "Short and extra-short forms of the Big Five Inventory-2: The BFI-2-S and BFI-2-XS," Journal of Research in Personality, 68, 69-81, 2017. doi:10.1016/j.jrp.2017.02.004.

[25] N. L. Siddiquei and D. R. Khalid, "The relationship between Personality Traits, Learning Styles and Academic Performance of E-Learners," Open Praxis, 10(3), 249, 2018. doi:10.5944/openpraxis.10.3.870.

[26] N. Zaric, S. Scepanović, T. Vujicic, J. Ljucovic, and D. Davcev, "The Model for Gamification of E-learning in Higher Education Based on Learning Styles," ICT Innovations 2017 Communications in Computer and Information Science, 265-273, 2017. doi:10.1007/978-3-319-67597-8 25.

[27] C.-H. Su and C.-H. Cheng, "A mobile gamification learning system for improving the learning motivation and achievements," Journal of Computer Assisted Learning, 31(3), 268-286, 2014. doi:10.1111/jcal.12088.

[28] K. S. Taber, "The Use of Cronbach's Alpha When Developing and Reporting Research Instruments in Science Education," Research in Science Education, 48(6), 1273-1296, 2017. doi:10.1007/s11165-016-9602-2.

[29] A. Christmann and S. V. Aelst, "Robust estimation of Cronbachs alpha," Journal of Multivariate Analysis, 97(7), 1660-1674, 2006. doi:10.1016/j.jmva.2005.05.012. 
[30] A. Ghasemi and S. Zahediasl, "Normality Tests for Statistical Analysis: A Guide for Non-Statisticians," International Journal of Endocrinology and Metabolism, 10(2), 486-489, 2012. doi:10.5812/ijem.3505.

[31] S. S. Shapiro and M. B. Wilk, "An analysis of variance test for normality (complete samples)," Biometrika, 52(3-4), 591-611, 1965.

[32] N. Nachar, "The Mann-Whitney U: A Test for Assessing Whether Two Independent Samples Come from the Same Distribution," Tutorials in Quantitative Methods for Psychology, 4(1), 13-20, 2008. doi:10.20982/tqmp.04.1.p013.

[33] A. J. Bishara and J. B. Hittner, "Testing the significance of a correlation with nonnormal data: Comparison of Pearson, Spearman, transformation, and resampling approaches.," Psychological Methods, 17(3), 399-417, 2012. doi: $10.1037 / \mathrm{a} 0028087$.

[34] A. Riswanto and S. Aryani, "Learning motivation and student achievement: description analysis and relationships both," COUNS-EDU: The International Journal of Counseling and Education, 2(1), 2017. doi:10.23916/002017026010. 